\title{
EQUIPAMENTOS DE MOVIMENTAÇÃO INTERNA CUSTOMIZAÇÃO X FLEXIBILIDADE*
}

Flaviana Dias Rocha Pimenta ${ }^{1}$ Suellen de Azevedo Torres ${ }^{2}$ Marcelo Dos Santos Milagres ${ }^{3}$

\section{Resumo}

Com o objetivo de adequar a logística interna ás particularidades e variabilidade das demandas de movimentação interna de produto, a VBR (Vallourec Tubos do Brasil S.A) estudou em parceria com o operador logístico TRADIMAQ um novo modelo de equipamento que atendesse todas as regras internas de segurança e as diversas restrições em sua operação. $O$ presente trabalho tem como objetivo apresentar as diferenças entre o modelo anterior utilizado para a movimentação interna e o atual modelo implementado no final de 2015, bem como todas as alterações necessárias entre o projeto conceitual e o equipamento em operação atualmente.

Palavras-chave: Logística interna; Operador logístico; Suprimentos.

\section{INTERNAL HANDLING EQUIPMENT CUSTOMIZATION X FLEXIBILITY IN VALLOUREC TUBOS DO BRASIL S/A}

\begin{abstract}
In order to bring domestic logistics the characteristics and variability of the product of internal movement demands that the VBR (Vallourec Tubos do Brasil S/A) studied in partnership with the logistics operator TRADIMAQ a new model of equipment that meets all internal rules security and various restrictions in operation. This study aims to present the differences between the previous model used for internal handling the current model implemented at the end of 2015 , as well as all the necessary changes between the conceptual design and the equipment currently in operation.
\end{abstract}

Keywords: Logistics; Logistics operator; Supply chain.

1 Pós-graduada em Gestão Estratégica de Logística, Coordenadora de Logistica, Superintendência de Planejamento e Logística, Vallourec Tubos do Brasil S.A, Belo Horizonte, Minas Gerais, Brasil.

2 Graduada em Sistema de Informação, Analista de Logistica, Superintendência de Planejamento e Logística, Vallourec Tubos do Brasil S.A, Belo Horizonte, Minas Gerais, Brasil.

3 Graduando em Tecnólogo de Logistica, Controlador de Logística, Superintendência de Planejamento e Logística, Vallourec Tubos do Brasil S.A, Belo Horizonte, Minas Gerais, Brasil. 


\section{INTRODUÇÃO}

Cada vez mais o processo de outsourcing nas empresas, que buscam focalizar sua estrutura em seu core business, impulsionam a contratação de operadores logísticos em busca de flexibilidade e produtividade na operação. Na logística, tornasse um fator chave a utilização de equipamentos que permitam flexibilidade de mercado sem perder as características especificas de cada operação, o que exige muitas vezes a customização de equipamentos e dispositivos de segurança específicos, restringindo a possibilidade de variações contratuais de equipamentos.

O processo de definição dos equipamentos a serem utilizados na contratação de um operador logístico exige um detalhamento de todas as demandas, particularidades e critérios de avaliação e variabilidade acordado, reduzindo ou até mesmo eliminando qualquer risco a operação. Segundo Fleury (2006), existe uma miopia que dificulta as empresas contratantes a visualizar o prestador de serviço como parceiro, e sim como um subalterno a qual a empresa não preocupa em integrar, onde cerca de $70 \%$ dos contratos terminam em conflito antes do prazo.

Várias pesquisas colaboram para este índice conforme Vendrametto, Oliveira Neto e Santos (2008), realizada no setor químico de carga seca, onde os fatores de maior impacto que prejudicaram a relação entre as empresas foram à inadequada e equivocada elaboração dos critérios, dos subcritérios e a elaboração do contrato com o operador logístico, entre eles: a) saúde financeira do operador logístico; b) falha na análise da capacidade técnica do operador para o serviço a ser oferecido; c) experiência no serviço e qualificação da equipe; e d) sistema de informação pouco confiável para o relacionamento.

Com isso, a elaboração detalhada do escopo contratado, incluindo as particularidades da empresa e das áreas internas, bem como a clara definição das expectativas e as regras de contrato para a variabilidade do mesmo e inovações do modelo atual, são fundamental para a parceria entre a empresa contratante e o operador logístico contratado. Com isso iremos apresentar neste trabalho, o case entre a VBR e o operador logístico TRADIMAQ na mudança dos equipamentos utilizados para a movimentação interna, focando nas adaptações necessárias mantendo o foco de contratar um equipamento que o mercado possa absorver ou ofertar com maior facilidade.

\section{MATERIAIS E MÉTODOS}

A VALLOUREC TUBOS do Brasil S.A é uma das mais modernas siderúrgicas integradas do mundo, produz tubos de aço sem costura a partir de matéria-prima e energia fornecidas pelas subsidiárias VALLOUREC FLORESTAL Ltda e VALLOUREC MINERAÇÃO Ltda. Um processo de produção auto-sustentável que credencia os seus produtos como Tubos Verdes.

A gerência de Logística Interna e Expedição de produtos da Vallourec Tubos do Brasil S.A (VBR) é a responsável por toda movimentação interna de tubos acabados e semi-acabados dentro da usina Barreiro, incluindo o transporte de tubos entre unidades de produção, equipamentos de manipulação de tubos nos pátios e nas área de produção e pelos equipamentos de apoio as áreas de manutenção e produção (não produto). Os fluxos de transporte se concentram em uma área de aproximadamente $1.200 .000 \mathrm{~m}^{2}$, envolvendo 120 pontos de carga e descarga diferentes de produtos, conforme figura 1. 

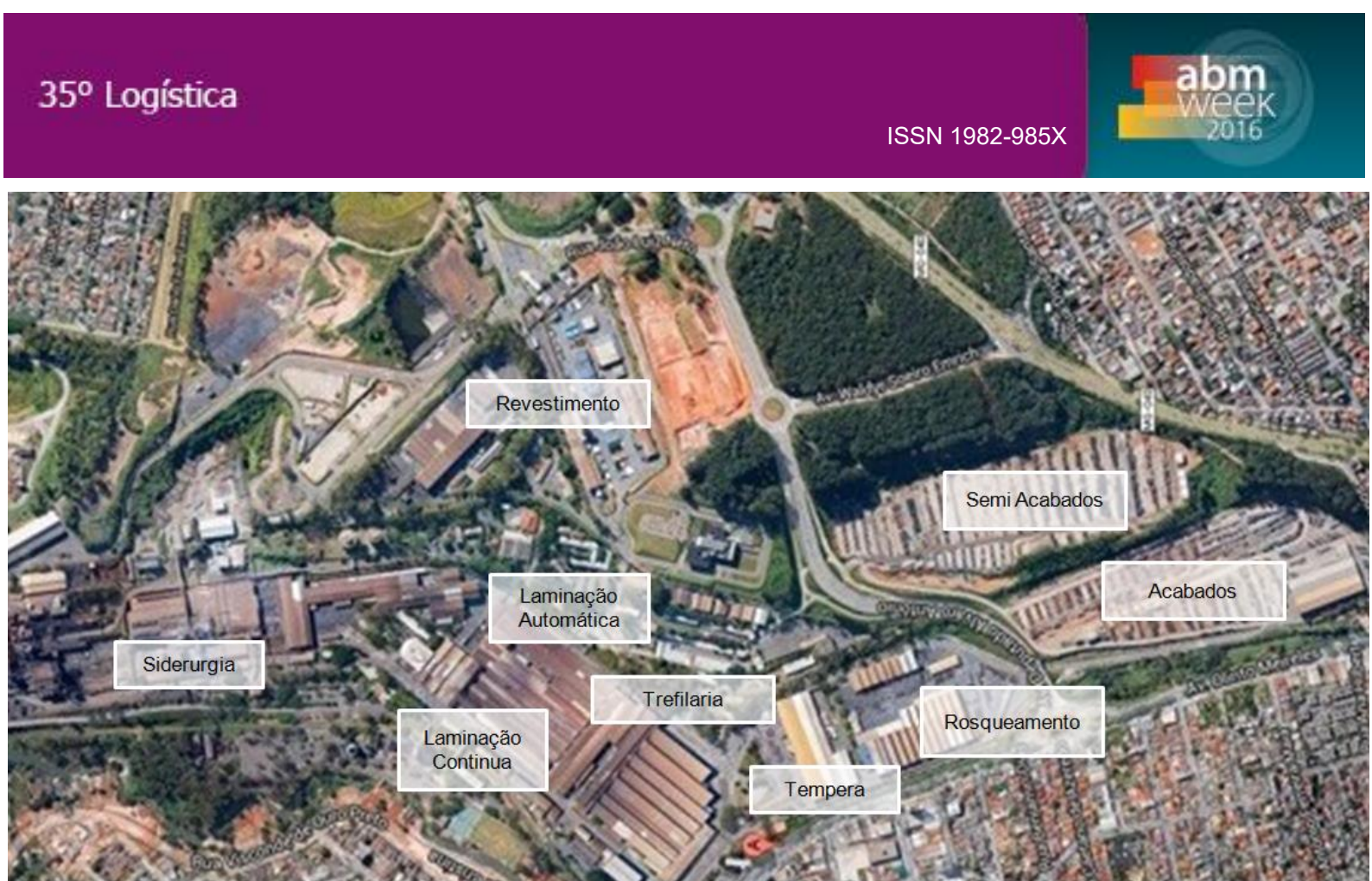

Figura 1 - Entradas e Saídas para movimentação interna

\subsection{Descrição do Problema}

Devido à complexidade da movimentação interna de materiais, entre cerca de 120 pontos de carga e descarga, a VBR possui equipamentos dedicados para esta atividade. Gerenciados através de uma central de equipamentos, operada pela VBR que é responsável por receber as demandas das áreas através de solicitações via sistema e a alocar as atividades para os equipamentos do operador logístico.

Em 2002, a VBR realizou uma grande mudança de paradigma ao alterar o modelo de equipamento utilizado, conforme figura 2 , de carretas convencionais com cavalos mecânicos e dedicados por área operacional, para carretas industriais com tratores agrícolas centralizados em uma central única de operações, o que possibilitou na época uma redução expressiva de custos.
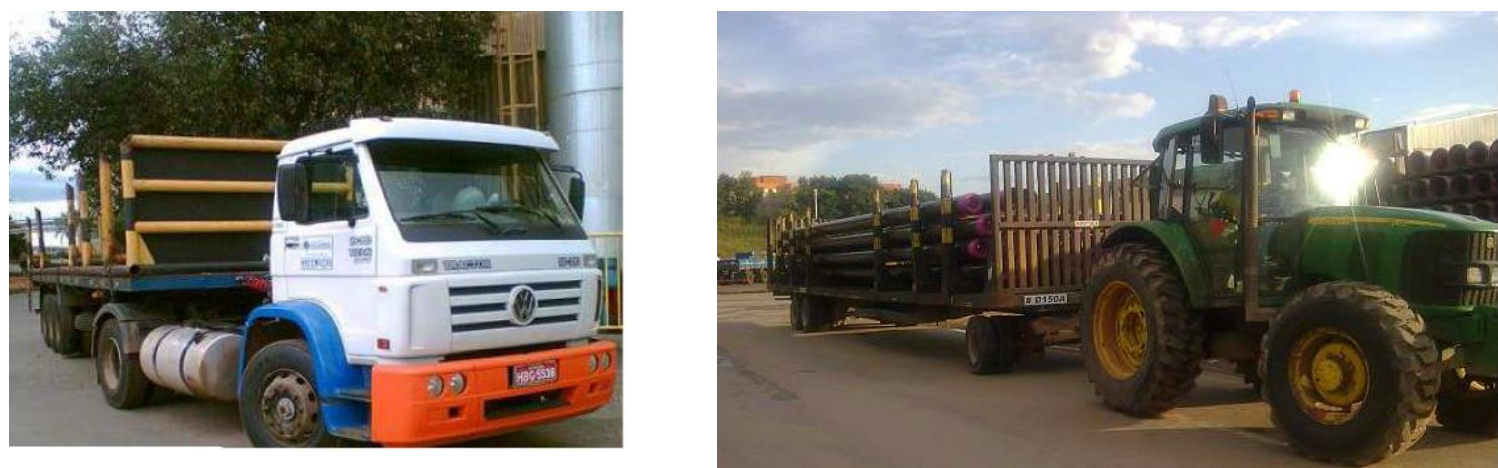

Figura 2: Carretas Convencionais e Cavalos Mecânicos X Carretas Industriais com tratores agrícolas.

Apesar do ganho em produtividade e operação dos equipamentos, devido a possibilidade de acoplamento e desacoplado do trator agrícola de forma rápida, com engate rápido e com isso a redução do número de tratores por carreta industrial, havia a falta de flexibilidade contratual devido a contratação de equipamentos totalmente customizados para a operação da VBR, incluindo toda a estrutura da carreta e seus componentes, como fueiros e anteparos. 
Existia a dificuldade nos períodos mobilização de equipamentos, onde era necessário adquirir equipamentos por período longo (devido depreciação do ativo) ou contratar carretas convencionais e cavalos mecânicos para os picos de operação perdendo o ganho operacional da substituição. Para os períodos de desmobilização, não era possível a aplicação dos equipamentos em outros segmentos devidos toda suas particularidades e customização.

Outro item importante era a produtividade baixa dos tratores agrícolas, nas operações interna da VBR onde os mesmos precisavam percorrer grandes distâncias internas, a velocidade máxima do mesmo e as restrições de capacidade de tração para aclives e declives. O que restringia a capacidade de carga da carreta em até 22 toneladas, apesar da capacidade da mesma de 30 toneladas.

Todos os fatores acima, somado ao período de oscilações de produção, ao realizar a cotação no mercado para a nova contratação de equipamentos para a movimentação interna em 2014, foi solicitado a todos os concorrentes que apresentassem equipamentos para atendimento a todas as particularidades e com flexibilidade de mercado.

\subsection{Mudança de Equipamento.}

\section{FASE 1 - Substituição do modelo de equipamento}

Durante o processo de cotação no mercado, houve várias propostas de equipamentos, sendo que a proposta tecnicamente e economicamente mais viável foi a ofertada pelo operador logístico TRADIMAQ. A proposta consistia na utilização de carretas rodoviárias e tratores terminais, conforme figura 3.

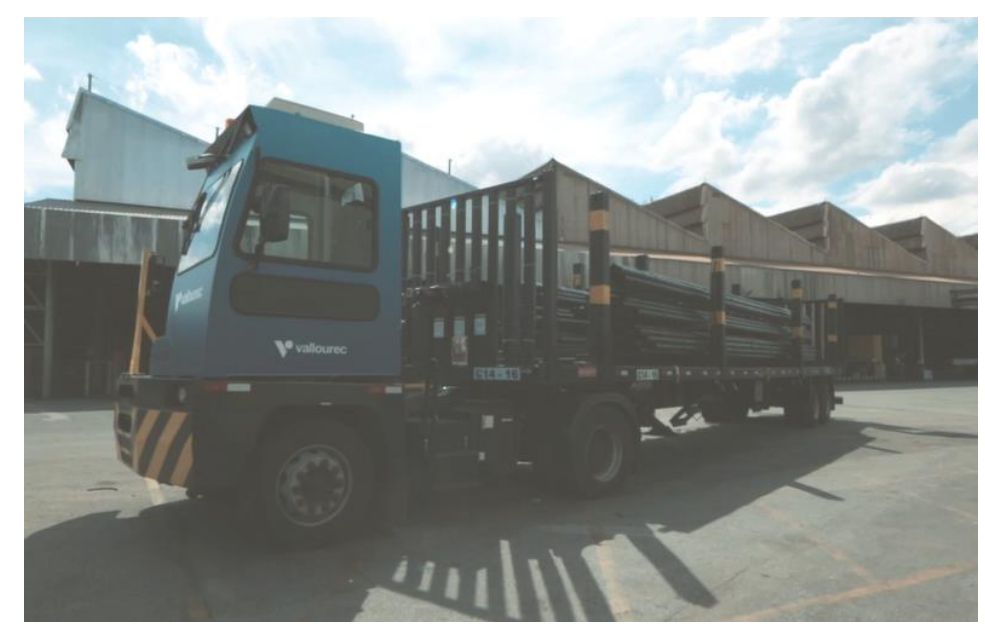

Figura 3 - Carreta rodoviárias e trator terminal.

Para a utilização deste equipamento, foram necessárias adequações a operação interna, sem perder a característica básica do equipamento de mercado, onde foi definido que as carretas rodoviárias permaneceriam com esqueleto conforme padrão e os tratores terminais os mesmos utilizados nas operações de terminais e outros.

Durante todo o processo de implantação do modelo, foram realizadas diversas adaptações ao projeto inicial em parceria como operador logístico TRADIMAQ e com as empresas Rosseti e Rucker. Segue abaixo alguns itens adaptados à operação da VBR. 


\section{Carretas Rodoviárias}

Para a operação na VBR foram realizadas algumas adaptações nas carretas rodoviárias da Rosseti, sem alterar a estrutura básica da mesma, mantendo a flexibilidade da mesma para o mercado no caso de desmobilização.

- Implantação de patola retrátil automática, devido às áreas de operação e vias de acesso com lombadas e a necessidade de operação com a carga alinhada (figura 4).

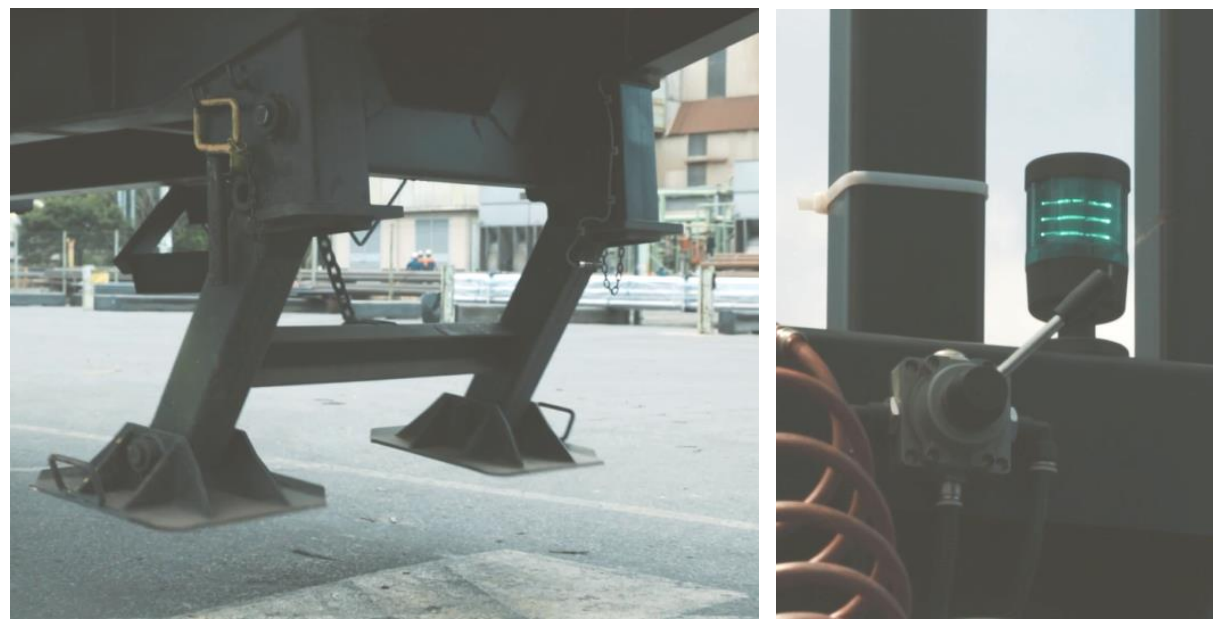

Figura 4 - Patola retrátil acionada via sistema pneumático

Com isso é possível realizar o acoplamento e desacoplamento da carreta de forma ágil e sem necessidade do operador do trator terminal descer do equipamento.

- Instalação de escadas de acesso, anteparo traseiro móvel e fueiro central, adequados ao processo de carregamento e descarregamento da mesma em áreas que não possui plataformas de carregamento e aos nossos materiais.
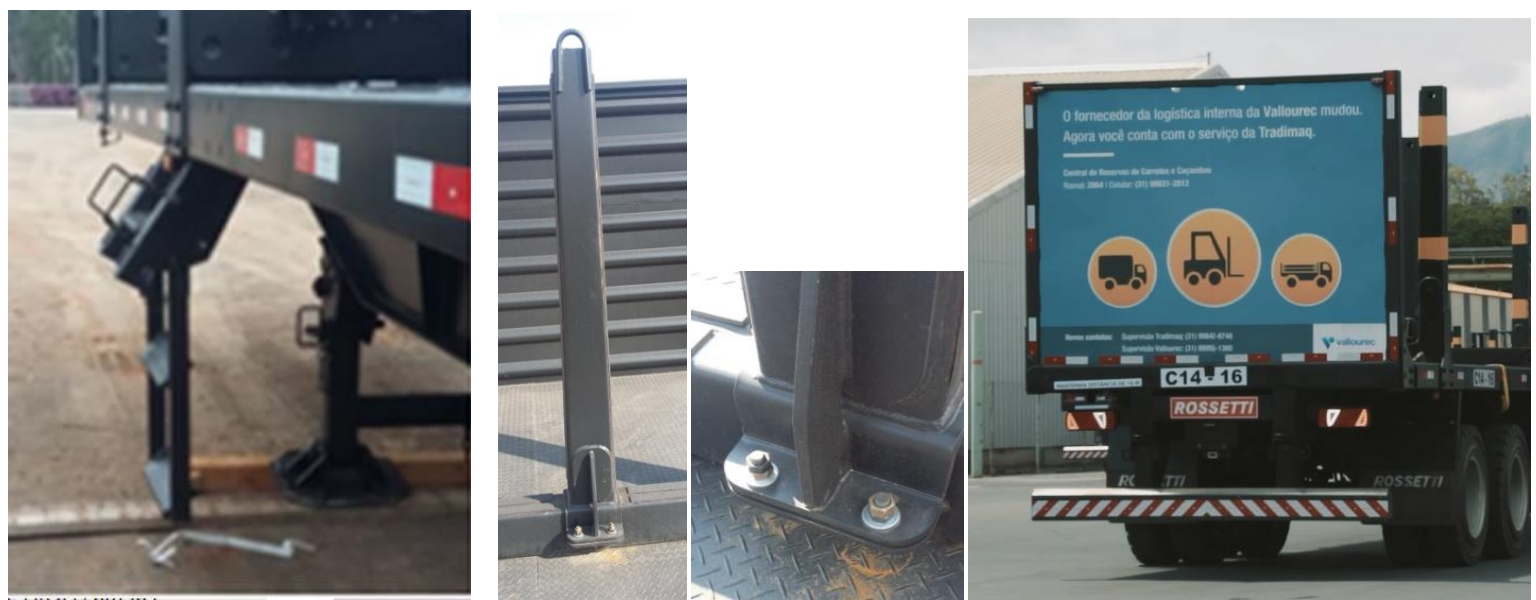

Figura 5 - Escada central, fueiro a anteparo traseiro móvel.

\section{Tratores terminais}

Os equipamentos para tração das carretas possuem maior capacidade de tração independente do aclive ou declive das áreas de destino, e com uma velocidade adequada a operação interna da VBR (limite máximo de $30 \mathrm{~km} / \mathrm{h}$ ), anteriormente era uma restrição com os tratores agrícolas.

Sensor para indicação de travamento do manípulo da $5^{\circ}$ roda, o que permite que dentro da cabine do trator confirmar se o procedimento foi realizado (figura 6). 


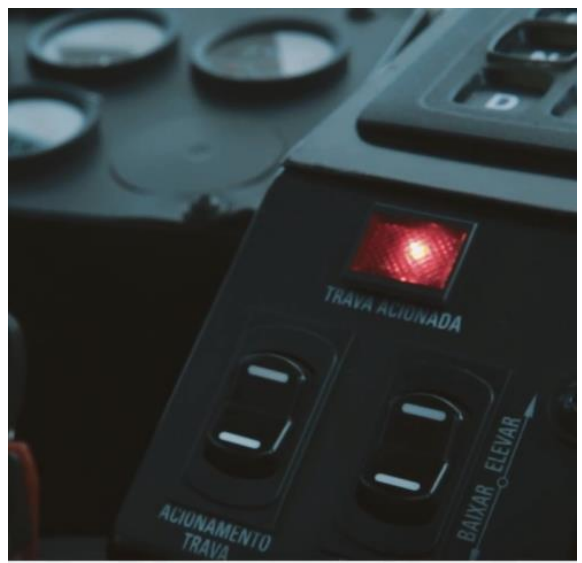

Figura 6 - Luz acessa: indica o travamento do manipulo da 5o roda.

\section{FASE 2 - Adequações após a fase de implantação}

A TRADIMAQ iniciou as operações na VBR em dezembro de 2015, substituindo os equipamentos e implementado diversos dispositis de segurança, como: câmeras de ré nos tratores terminais e carretas, revestimento móvel em todos os fueiros, o que possibilitou ganho de qualidade na movimentação de materiais e segurança nas manobras de entrada e saída dos pontos de carga e descarga.

Durante os 3 primeiros meses de operação, foram constatados 2 riscos operacionais relacionados a substituição dos equipamentos, e os mesmos foram tratados da seguinte forma:

Patola (pés) da carreta não posicionada de forma correta, gerando o risco de "queda" da carreta ao realizar o desacoplamento da mesma, para este risco a TRADIMAQ instalou sensores na patola que confirma se a patola está posicionada da forma correta e permite o desengate do trator terminal apenas no caso de presença da patola na posição correta (apoiada no chão), garantindo a segurança na operação de desacoplamento.

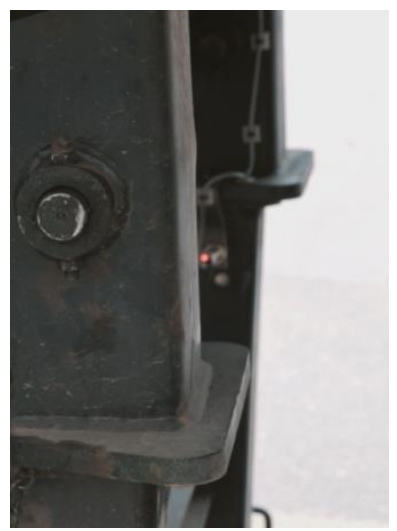

Figura 7 - Sensor de presença e posicionamento da patola.

Acoplamento errado ou não acoplamento do pino rei na 5ำ roda, gerando o risco na operação de queda da carreta ao ser tracionada devido à falta de engate do pino com a 5 - roda. Para esta situação a TRADIMAQ instalou uma válvula, figura 8, que é acionada pelo sensor de presença do pino rei. Com este sensor é liberado 0 ar para levantar a patola e liberar a carreta, na ausência do pino rei na posição a carreta fica freada e o sistema de subir não possui ar para funcionar, impedindo desta forma que a mesma desloque sem o acoplamento correto. 


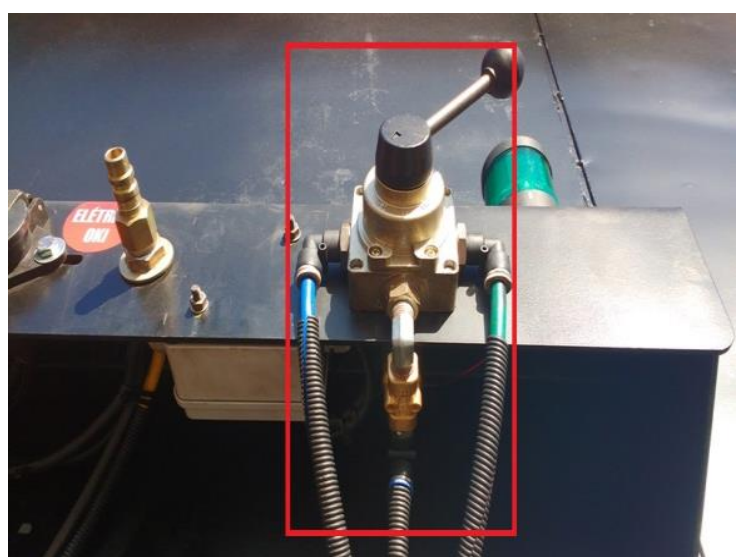

Figura 8 - Válvula e ar para acoplamento e uso da patola pneumática.

Todas estas ações foram realizadas internamente pelo operador logístico TRADIMAQ e com a validação da VBR, reforçando desta forma a parceria entre as empresas, e resguardando a segurança das operações internas, que exige dos equipamentos inúmeros engates e desengates ao longo do dia, processo diferente da operação destes equipamentos em outros processos.

\section{CONCLUSÃO}

Com a operação com trator terminal, foi possível aumentar a capacidade de carregamento das carretas, mesmo com os aclives e declives das áreas, com o ganho em $36 \%$ na capacidade de carga. O tempo de deslocamento dos tratores terminais com relação aos tratores agrícolas, teve um ganho de $37 \%$ devido a agilidade nos trajetos e performance do equipamento. $O$ que possibilitou a redução de $30 \%$ na quantidade de carretas e $40 \%$ nos equipamentos de tração.

Os custos de depreciação da carreta rodoviária representaram uma redução de $30 \%$ comparada ao custo das carretas industriais anteriores, e possibilita para a VBR conforme contrato previsto com a TRADIMAQ a flexibilidade contratual em caso de desmobilização e mobilização contratual com maior agilidade e clareza.

Com todos os dispositivos instalados focados em segurança como: câmeras, fueiros, anteparos e sensores, conseguimos oferecer um serviço interno com maior segurança e com a flexibilidade contratual necessária para garantir as operações da VBR em parceria com o operador logístico TRADIMAQ.

\section{REFERÊNCIAS}

1 RIBEIRO. Aline. Gestão do Relacionamento com Prestadores de Serviços Logísticos IN. FLEURY, P. F: WANKE, P: FIGUEIREDO, K. F. Logística e gerenciamento da cadeia de suprimentos: planejamento do fluxo de produtos e dos recursos. São Paulo: Atlas, 2006.

2 VENDRAMETTTO, O.; OLIVEIRA NETO, G.C.; SANTOS, O.S. Gestão de Materiais e Operador Logístico um caso de relacionamento mal sucedido. Anais - ENEGEP 2008. www.abepro.org.br. 